\section{DOMESTIC CORRESPONDENCE.}

To the Editor of The Journal of the American Medical Association:

In the Journal for February 16,1884 , there is an editorial on the subject of the new medical law of Virginia. 'The writer of the editorlal says that one of the "legitimate objects to be accomplished by legislative enactments for regulating the education and practice of the medical profession, should consist of a simple provision by which the certificates of similar bodies in other States should be recognized, so as to maintain a comity of rights and interests between the States."

That such a recognition of the certificates issued by the Board of one State by the Board of another would be very desirable, there can be no question; but so long as the Boards differ so widely in their requirements as they now do, I do not see how such recognition could be made. For example, in many of the States all that is required is that the candidate should be a graduate of some respectable medical college, the question of respectability being left to the discretion of the Board. In other States-California, for instance-there are two, or possibly three, examining Boards, one representing the regular profession, one homoepathic, and probably one eclectic, though I am not sure on this latter point. When in California a few years ago, I was told by a member of the regular Board that most incompetent men had been passed by the homøopathic Board of that State. Now, would it be reasonable or proper for the Alabama Board, for instance, which is admirably constituted, to "recognize" the certificate of a physician coming from California, without subjecting him to an examination?

As a member of the committee which framed the Virginia law, I do not hesitate to say that our object was not only to put down notorious quackery, but to check that more dangerous, because less conspicuous, ignorance which is concealed behind a diploma of some medical college whose standard is wretchedly low. To do this it was necessary that every applicant for practice, whether a graduate or not, should be required to pass a satisfactory examination before a board of examiners, and it was with reference to this point that the committee had most trouble, an effort being made to allow any man having a diploma from any college to practice without standing an examination.

The medical colleges in the United States are so numerous now, and the competition for students so great, that the temptation to lower the standard required for graduation in order to attract students, becomes almost irresistible, and in view of this fact, the desirability of having an examining board in each State entirely independent of the colleges becomes apparent. Then, the next step will be to have some concert of action among the boards of the different States, so as to make the standard required by the different boards correspond. If many of the States will do this, then the colleges will be forced to raise their standard for graduation.
I hope to be able to bring this matter before those interested in the subject at the next meeting of the American Medical Association, and if you approve of the plan, I trust you will call attention to it through the columns of the JOURNAL.

Very respectfully \&c., WM. C. DABNEY, M.D.

Charlottsville, Va., Feb. 22, 1884 .

Note. - In the editorial alluded to in the above letter, we meant by the words "similar boards in other States," only such as were constituted on the same basis and exercised the same powers and duties. We do not regard a State Board of Examiners, who are required to issue licenses to practice to any party who may possess a college diploma, as in any sense "similar," to the board provided for by the Virginia law. Indeed, such boards are practically little more than registration offices, and the laws establishing them are hardly worth the paper they are printed on. -EDITOR.

\section{FOREIGN CORRESPONDENCE.}

$$
\text { Paris, Feis. 8, i } 884 .
$$

Prof. Germain Sée and Dr. Bochefontaine, his "chef de laboratoire" at the Hotel Dieu, lately undertonk a series of experiments as to the physiological action of the sulphate of quinine, which were afterward compared with the results obtained clinically at the hospital. The following is a summary of their paper on the subject which was read at a recent meeting of the Academy of Sciences:

In the healthy human subject, the sulphate of quinine lowers the temperature to a very insignificant degree; the oxidations, however, undergo marked diminution; the pulse becomes slower, and the bloodpressure is lowered. In the typhic patient, the temperature is lowered after the first gramme, and particularly after the second gramme of quinine; it falls one degree and a half in six or eight hours, and the effect persists for a day and a half. The oxidations diminish in the same proportion. The pulse-rate becomes much slower than in the physiological state. The blood-pressure, which falls constantly under the influence of hyperthermia, rises to the normal condition; there is, besides, increase of the contractile energy of the heart. The sulphate of quinine alone preserves the force of the heart and increases it. Moreover, as it diminishes the febrile heat directly, without previously increasing the combustion, as is the case witl cold baths, it stops dicrotism, and the arterial tension, which was considerably diminished, resumes its normal strength. It is therefore a powerful antipyretic. If, in the physiological state, it diminishes vascular pressure, it is because it does not prodice a marked diminution of the normal temperature.

A very interesting exhibition of the wonders of the deep in the form of submarine animals and plants, is about to be opened at the Jardin des Plantes, which were collected by M. Alphonse Milne-Edwards during his exploration cruise along the western coast of 